\title{
Fatores que afetam a disponibilidade do fósforo e o manejo da adubação fosfatada em solos sob sistema plantio direto
}

\author{
Factors affecting the phosphorus availability and the fertilization management \\ in no-tillage system
}

\author{
Danilo Rheinheimer dos Santos*I Luciano Colpo GatiboniI João Kaminski ${ }^{\text {I }}$
}

- REVISÃO BIBLIOGRÁFICA -

\section{RESUMO}

A compreensão dos fenômenos básicos da dinâmica do fósforo no solo é importante para a tomada de decisão sobre a necessidade de adição e para a definição das doses e dos modos de aplicação de fertilizantes fosfatados. As formas e o grau de labilidade do fósforo variam com as características e propriedades do solo. Em solos jovens, os fosfatos de cálcio são os principais fornecedores de fósforo aos organismos vivos. Por outro lado, em solos altamente intemperizados, a biociclagem dos fosfatos orgânicos assume grande importância na manutenção da biodisponibilidade, embora não seja suficiente para a obtenção da máxima produtividade econômica das culturas comerciais. Nos solos tropicais e subtropicais cultivados, o controle dos teores de fósforo em solução é feito predominantemente pelo fosfato adsorvido aos grupos funcionais dos colóides inorgânicos. $O$ diagnóstico da disponibilidade de fósforo é feito pela análise de solos por diferentes metodologias, cada uma com suas vantagens e limitações. A tomada de decisão em adicionar ou não fosfatos ao solo e a definição da dose a ser aplicada dependem muito mais da calibração, baseada na relação entre os teores de fósforo extraídos e a produtividade das plantas, do que do método de extração. A elevação dos níveis de disponibilidade de fósforo até a faixa ótima pode ser feita de forma corretiva ou gradativa. A adubação corretiva com incorporação em todo o volume de solo é mais eficiente e, talvez, a única alternativa para a correção da carência de fósforo do solo das camadas subsuperficias. A aplicação superficial de fertilizantes fosfatados no sistema plantio direto parece não ser uma boa alternativa econômica e pode se tornar um problema ambiental. Desse modo, devem-se intensificar as pesquisas enfocando, entre outras: (a) as frações de fósforo no solo e a produtividade das culturas; (b) as formas de aplicação dos fertilizantes fosfatados no solo sob sistema plantio direto; (c) as relações entre a disponibilidade de fósforo nas camadas subsuperficiais (abaixo de $10 \mathrm{~cm}$ ), a presença de alumínio trocável e de camadas compactadas $e$ (d) o monitoramento constante das transferências de fósforo dos solos aos sistemas aquáticos.

Palavras-chave: adsorção e dessorção de fósforo, colóides, métodos de análise, produtividade.

\section{ABSTRACT}

The basic phenomena of phosphorus dynamics in soil is important to define the rate and application manners of phosphates fertilizers. The forms and availability of phosphorus vary with the soil characteristics and properties. In young soils, the calcium phosphates are the main source to organisms. On the other hand, in highly weathered soils the organic phosphorus cycling assumes great importance in the maintenance of the biological bioavailability, although it is insufficient to economical crop productivity. In tropical and subtropical cultivated soils, the soil phosphorus in solution is controlled by phosphorus adsorbed at functional groups of inorganic colloids. The phosphorus diagnosis is made by soils analysis at different methodologies, each one with their advantages and limitations. The decision on adding phosphate and to the rate define is more dependent on the calibration between the value extracted with the crop yield than the extraction method. The elevation of phosphorus availability can be made in corrective or gradual addition. The corrective fertilization is more efficient, and maybe the only alternative, for phosphorus deficiency correction in deeper soil layers. The correction of phosphorus deficiency in deeper layers after the no-tillage system adoption is difficult. The superficial phosphate application in no-tillage seems not to be a good economical alternative and can become an environmental problem. The research must be intensified focusing among others: (a) phosphorus fractions in soil and crop yield; (b) phosphates

IDepartamento de Solos, Centro de Ciências Rurais (CCR), Universidade Federal de Santa Maria (UFSM), 97105-900, Santa Maria,

RS, Brasil. Email: danilo@ccr.ufsm.br. *Autor para correspondência.

IICentro Educacional do Oeste, Universidade Estadual de Santa Catarina (UDESC), Chapecó, SC, Brasil. 
fertilizers application in no-tillage system; (c) relation of phosphorus availability with exchangeable aluminum and compacted soil layers in soil deep; (d) monitoring of transferred phosphate from soil to aquatic systems.

Key words: phosphorus adsorption and desorption, colloids, analysis methods, yield.

\section{INTRODUÇÃO}

O fósforo ocorrente no solo, de interesse agronômico ou ambiental, é constituído por compostos derivados do ácido ortofosfórico e, menos comumente, dos pirofosfatos. Os minerais primários fosfatados comuns em rochas são as apatitas, de onde são liberados durante a intemperização, resultando em minerais secundários mais estáveis termodinamicamente, ou incorporados a compostos orgânicos biologicamente.

A dinâmica do fósforo no solo está associada a fatores ambientais que controlam a atividade dos microrganismos, os quais imobilizam ou liberam os íons ortofosfato, e às propriedades físicoquímicas e mineralógicas do solo. Assim, em solos jovens e nos moderadamente intemperizados, como os Vertissolos, Chernossolos e os Neossolos, ainda ocorre fósforo em minerais primários, mas a maior parte deste elemento se encontra na forma orgânica (Po), ou na forma mineral $(\mathrm{Pi})$, adsorvida fracamente aos minerais secundários. Nos solos altamente intemperizados, como os Latossolos, predominam as formas inorgânicas ligadas à fração mineral com alta energia e as formas orgânicas estabilizadas física e quimicamente. De acordo com o maior ou menor grau de estabilidade destes compostos, são enquadrados como fosfatos lábeis e não-lábeis. A fração lábil é representada pelo conjunto de compostos fosfatados capazes de repor rapidamente a solução do solo, quando ele é absorvido por plantas ou por microrganismos. Por isso, as frações mais lábeis são dependentes do grau de intemperização do solo, da mineralogia, da textura, do teor de matéria orgânica, das características físico-químicas, da atividade biológica e da vegetação predominante (WALKER \& SYERS, 1976; CROSS \& SCHLESINGER, 1995). Assim, os processos geoquímicos e biológicos transformam os fosfatos naturais em formas orgânicas e inorgânicas estáveis e transferem o fósforo entre os compartimentos do ambiente.

Esta revisão apresenta uma discussão sobre as diferentes formas e a dinâmica do fósforo no solo, a predição de sua disponibilidade e as possibilidades de correção de sua deficiência pela adição de fertilizantes, com ênfase no sistema plantio direto.
Formas e dinâmica de fósforo no solo

Em termos práticos, a divisão das formas de fósforo no solo é fundamentada nos extratores usados para estimá-las. CHANG \& JACKSON (1957) desenvolveram um método de fracionamento das formas de fósforo, que estabeleceu as bases para a sua identificação de acordo com o extrator usado para acessá-las. A partir daí, foi dada maior ênfase a estudos que identificavam a predominância de determinada fração no solo e a contribuição daquelas preferencialmente absorvidas pelas plantas (NOVAIS \& SMYTH, 1999). No entanto, deve ser destacado que nem todas as formas são passíveis de quantificação com a exatidão desejada, pois não há limites nítidos entre elas. Isso é decorrente de sua distribuição em ampla faixa de forças de retenção, em diferentes grupos funcionais, resultantes do grau de intemperismo a que foi submetido o material que deu origem ao solo.

Para entender a sua dinâmica, o fósforo do solo é dividido em dois grandes grupos, fósforo inorgânico (Pi) e fósforo orgânico (Po), dependendo da natureza do composto a que está ligado. O grupo do Pi pode ser separado em duas partes, o fósforo dos minerais primários e o fósforo adsorvido. Ele compõe um intrincado grupo de fosfatos inorgânicos, formando diferentes compostos e com diferentes graus de estabilidade química. Pode ser encontrado ligado aos grupos funcionais silanol e aluminol das arestas das argilas silicatadas e nos R-OH dos oxihidróxidos de ferro e alumínio e, inclusive, adsorvido à matéria orgânica do solo através de pontes de cátions. A adsorção do fosfato aos oxihidróxidos de ferro e alumínio ocorre, principalmente, nas formas de baixa cristalinidade e com alto desbalanço de cargas. Esta adsorção se dá nos sítios ácidos de Lewis, onde os grupos $\mathrm{OH}$ e $\mathrm{OH}_{2}{ }^{+}$ligados mono e tricordenadamente ao metal ( $\mathrm{Fe}$ ou $\mathrm{Al}$ ) são trocados pelo fosfato, caracterizando o fenômeno de troca de ligantes (BARROW, 1983). O fosfato pode ligar-se em formas monodentadas, em que um oxigênio do fosfato é ligado ao metal; bidentadas, em que dois oxigênios são ligados ao metal; e binucleadas, em que dois oxigênios do fosfato são ligados a dois átomos do metal. A energia de ligação é crescente para os compostos monodentados, bidentados e binucleados e a possibilidade de dessorção do fosfato aumenta na ordem inversa (PARFITT, 1989). Com o passar do tempo, pode ocorrer o "envelhecimento" do fósforo adsorvido, cujas ligações tendem à especificidade, formando compostos binucleados ou ainda a penetração do fosfato nas imperfeições do mineral cristalizado. Isso resulta em maior estabilidade e menor possibilidade de dessorção do fosfato. A magnitude 
da adsorção depende da quantidade de constituintes com capacidade de adsorver moléculas neutras ou carregadas eletricamente. Nos solos de regiões tropicais e subtropicais, os óxidos de ferro malcristalizados, a quantidade de alumínio substituindo ferro e, em menores quantidades, os óxidos bemcristalizados e a caulinita são os principais responsáveis por esse fenômeno.

O fósforo orgânico pode constituir de 5 a $80 \%$ do fósforo total do solo e, nos solos tropicais, é fonte de fósforo às plantas e deve ser levado em consideração em estudos envolvendo a sua dinâmica e a biodisponibilidade (RHEINHEIMER \& ANGHINONI, 2003). O fósforo orgânico é originário dos resíduos vegetais adicionados ao solo, do tecido microbiano e dos produtos de sua decomposição (RHEINHEIMER et al., 2000a; CONTE et al., 2002 e 2003; MARTINAZZO et al., 2007). A grande variedade de compostos orgânicos no solo faz com que mais da metade das formas de fósforo orgânico ainda não tenham sido identificadas. As principais formas já identificadas são os fosfatos de inositol, que compõem de 10 a $80 \%$ do fósforo orgânico total, os fosfolipídios (0,5 a 7\%), ácidos nucléicos ( 3\%) e outros ésteresfosfato (>5\%). A estabilidade destes compostos depende de sua natureza e de sua interação com a fração mineral, pois são usados como fonte de carbono e elétrons pelos microrganismos, cujo resultado é a sua mineralização e disponibilização do fósforo. Alguns compostos, como ácidos nucléicos e fosfolipídios com ligação diéster, possuem estrutura química que facilita sua decomposição, sendo facilmente mineralizáveis e, por isso, as quantidades armazenadas no solo são pequenas. Já os fosfatos monoésteres, como o fosfato de inositol, apresentam alta energia de ligação com a estrutura química da molécula e alta carga residual, o que lhes confere facilidade de interação com os constituintes inorgânicos do solo. Isso dificulta a mineralização e favorece o acúmulo no solo, sendo de baixa labilidade e disponibilidade às plantas (RHEINHEIMER et al., 1999 e 2002).

Assim, sob o ponto de vista da fertilidade do solo, independentemente da natureza química, o fósforo é dividido de acordo com a facilidade com que repõe a solução do solo. A separação do fósforo em formas lábeis, moderadamente lábeis e não lábeis, mesmo que essa subdivisão seja imprecisa, ajuda no entendimento da dinâmica da disponibilidade do fósforo. Para estudos do acúmulo e dessorção dessas formas de fósforo de acordo com sua labilidade, diversos autores têm utilizado a técnica de fracionamento proposta por HEDLEY et al. (1982). Essa usa, seqüencialmente, extratores com diferentes forças de extração, os quais removem Pi e Po das formas mais fracamente retidas até as mais estáveis. Com as modificações propostas por CONDRON et al. (1985), os extratores utilizados no fracionamento são: resina trocadora de ânions - RTA (Pi), $\mathrm{NaHCO}_{3} 0,5 \mathrm{~mol} \mathrm{~L}^{-1} \mathrm{a}$ pH 8,5 (Pi e Po); NaOH 0,1 mol L-1 (Pi e Po); $\mathrm{HCl} \mathrm{1,0mol}$ $\mathrm{L}^{-1}(\mathrm{Pi}), \mathrm{NaOH} 0,5 \mathrm{~mol} \mathrm{~L}^{-1}$ (Pi e Po); e digestão com $\mathrm{H}_{2} \mathrm{SO}_{4}$ $+\mathrm{H}_{2} \mathrm{O}_{2}+\mathrm{MgCl}_{2}\left(\mathrm{P}_{\mathrm{i}}+\mathrm{P}_{\mathrm{o}}\right)$.

Estudos utilizando o fracionamento de Hedley têm mostrado que as frações orgânicas e inorgânicas de fósforo no solo podem atuar como fonte ou dreno para a solução do solo, dependendo das suas características mineralógicas, das condições ambientais, da adubação e do manejo do solo. Em sistemas naturais, onde não há adição de fósforo, a sua disponibilidade está intimamente relacionada à ciclagem das formas orgânicas. Já em solos pouco intemperizados ou adubados, têm se observado que grande parte do fósforo disponível é tamponado pelas frações inorgânicas lábeis, enquanto que, em solos altamente intemperizados ou sem adubação, a disponibilidade de fósforo é altamente dependente das formas inorgânicas e orgânicas de labilidade intermediária (NOVAIS \& SMITH, 1999).

Com a adição de fertilizantes fosfatados, há o acúmulo de fósforo em formas inorgânicas e orgânicas com diferentes graus de energia de ligação, embora o acúmulo das formas inorgânicas seja mais pronunciado. A redistribuição de fósforo em diversas formas quando da adubação também ocorre em solos cultivados sob sistema plantio direto. Observa-se a formação de uma camada na superfície do solo com alta disponibilidade de nutrientes, principalmente de fósforo (RHEINHEIMER \& ANGHINONI, 2001). Esse comportamento é conseqüência da adição consecutiva de fertilizantes na camada superficial, ausência de revolvimento e diminuição das taxas de erosão. A adsorção do fósforo ocorre primeiramente nos sítios mais ávidos (de menor labilidade) e, posteriormente, o fósforo remanescente é redistribuído em frações retidas com menor energia e de maior disponibilidade às plantas, comparativamente ao sistema de cultivo convencional (RHEINHEIMER et al., 2000b).

Em função da baixa mobilidade do fósforo no solo, a adição de fertilizantes na superfície no sistema plantio direto tem, paulatinamente, saturado os sítios de maior afinidade por fósforo, o que pode ser observado nas diferenças no fósforo previamente adsorvido $\left(\mathrm{P}_{\text {pre }}\right)$. Por exemplo, RHEINHEIMER et al. (2003a) observaram que o $\mathrm{P}_{\text {pre }}$ no solo Latossolo Vermelho distroférrico, coletado em Santa Rosa - RS, perfez 21, 18 e 11\% da capacidade de adsorção máxima de fósforo $\left(\mathrm{P}_{\max }\right)$ no sistema plantio direto e 18, 20 e 
$14 \%$ no cultivo convencional, para as camadas $0-2,5$; 2,5-7,5 e 7,5-17,5cm, respectivamente, não tendo diferenças quanto aos métodos de preparo. No Latossolo Vermelho distrófico, coletado em Passo Fundo -RS, a contribuição do $\mathrm{P}_{\text {pre }}$ foi de 29 e 12\% (0$17,5 \mathrm{~cm})$ da $P_{\max }$ para o sistema plantio direto e cultivo convencional, respectivamente. No solo Argissolo Vermelho distrófico, coletado em Eldorado do Sul RS, o $\mathrm{P}_{\text {pre }}$ perfez 39, 18 e 5\% da $\mathrm{P}_{\max }$ sob sistema plantio direto e 27,21 e $8 \%$ da $\mathrm{P}_{\max }$ sob cultivo convencional, para as camadas $0-2,5 ; 2,5-7,5$ e 7,5-17,5cm, respectivamente (Tabela 1 ). A contribuição percentual do $\mathrm{P}_{\text {pre }}$ da camada superficial dos solos sob SPD foi inversamente proporcional ao seu teor de argila e óxidos de ferro. Isso está de acordo com o fato de que a magnitude da adsorção depende da quantidade de constituintes com capacidade de adsorver moléculas neutras ou carregadas eletricamente.

Diversos autores reportam às frações menos lábeis uma atuação de fonte ou de dreno do fósforo disponível quando a quantidade de fósforo adicionada via fertilizantes é maior que a quantidade exportada pelo sistema (absorção das plantas e perdas), a porção remanescente é estabilizada em formas de labilidade intermediária, que atuam como dreno do fósforo adicionado. Por outro lado, quando a adição de fertilizantes é aquém da exportação de fósforo do sistema, as formas de fósforo de labilidade intermediária atuam como fonte, mantendo os teores da solução do solo (RHEINHEIMER \& ANGHINONI, 2001; CONTE et al., 2003; GATIBONI et al., 2007).

Em solos sob sistema plantio direto, com acúmulo de fósforo na camada superficial, observa-se, após esgotamento do fósforo do solo por cultivos sucessivos, que todas as formas de fósforo do fracionamento de Hedley podem atuar como tamponantes e disponibilizar formas solúveis de fósforo. Nos solos com menor acúmulo de fósforo pela adubação, as formas orgânicas são fontes potenciais de $\mathrm{P}$ às plantas, porém com fornecimento abaixo da

Tabela 1 - Capacidade de sorção máxima $\left(\mathrm{P}_{\max }\right)$ e fósforo previamente sorvido $\left(\mathrm{P}_{\mathrm{pre}}\right)$ em diferentes solos, métodos de preparos e profundidade de amostragem (RHEINHEIMER et al., 2003a).

\begin{tabular}{|c|c|c|c|c|c|}
\hline Solo & Preparo & Camada & $\mathrm{P}_{\max }^{3}$ & $\mathrm{P}_{\mathrm{pre}}^{4}$ & $\mathrm{P}_{\text {pre }}$ \\
\hline & & $\mathrm{cm}$ & 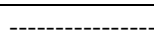 & - & $\%$ do $\mathrm{P}_{\max }$ \\
\hline \multirow[t]{6}{*}{$\operatorname{LVdf}^{1}$} & $\mathrm{SPD}^{2}$ & $0-2,5$ & 1182 & 248 & 21 \\
\hline & & $2,5-7,5$ & 1204 & 223 & 18 \\
\hline & & $7,5-17,5$ & 1200 & 133 & 11 \\
\hline & SCC & $0-2,5$ & 972 & 176 & 18 \\
\hline & & $2,5-7,5$ & 1024 & 202 & 20 \\
\hline & & $7,5-17,5$ & 1099 & 158 & 14 \\
\hline \multirow[t]{6}{*}{ LVd } & SPD & $0-2,5$ & 880 & 261 & 30 \\
\hline & & $2,5-7,5$ & 851 & 241 & 28 \\
\hline & & $7,5-17,5$ & 878 & 250 & 28 \\
\hline & SCC & $0-2,5$ & 777 & 99 & 13 \\
\hline & & $2,5-7,5$ & 842 & 105 & 12 \\
\hline & & $7,5-17,5$ & 890 & 109 & 12 \\
\hline \multirow[t]{6}{*}{ PVd } & SPD & $0-2,5$ & 427 & 165 & 39 \\
\hline & & $2,5-7,5$ & 454 & 83 & 18 \\
\hline & & $7,5-17,5$ & 703 & 32 & 5 \\
\hline & SCC & $0-2,5$ & 316 & 86 & 27 \\
\hline & & $2,5-7,5$ & 362 & 77 & 21 \\
\hline & & $7,5-17,5$ & 500 & 42 & 8 \\
\hline
\end{tabular}

${ }^{1}$ LVdf = Latossolo Vermelho Distroférrico típico; LVd = Latossolo Vermelho Distrófico típico; PVd = Argissolo Vermelho Distrófico típico. ${ }^{2} \mathrm{SPD}=$ sistema plantio direto e SCC = sistema de cultivo convencional.

${ }^{3} \mathrm{P}_{\max }=$ capacidade de sorção máxima.

${ }^{4} \mathrm{P}_{\text {pre }}=$ fósforo previamente sorvido.

Ciência Rural, v.38, n.2, mar-abr, 2008. 
demanda. Embora o fracionamento de Hedley seja importante para o acompanhamento das diferentes formas de P no solo, uma única extração com Mehlich 1 ou resina ainda continuam sendo melhores indicadores da biodisponibilidade de fósforo (GATIBONI et al., 2007).

Métodos de análises de fósforo disponível no solo

A avaliação do fósforo disponível é feita geralmente com o uso de soluções extratoras, ou agentes de troca iônica, que visam à quantificação de formas capazes de repô-lo à solução do solo após absorção pelas plantas. Os modelos de disponibilização consideram dois compartimentos interligados: a solução do solo, que constitui o fator intensidade (I), e a fase sólida, que armazena os fosfatos que abastecem a solução, lábeis ou moderadamente lábeis, denominado fator quantidade (Q). A cinética de como o primeiro compartimento é abastecido pelo segundo, chamado fator capacidade (C), representa o poder tampão, ou a taxa de recomposição do I pelo Q, a qual é controlada pela energia de ligação do nutriente em $Q$ e pela difusividade para I, ou pelo grau de labilidade. No caso do fosfato, quanto maior o valor de $\mathrm{Q}$, menor a energia de ligação aos colóides, pois os sítios de maior avidez já estão saturados. Por isso, os métodos de avaliação da fertilidade do solo procuram estimar a porção de Q passível de repor I, para predizer a necessidade de suplementação do nutriente. A eficiência desses métodos depende da forma físico-química em que o nutriente está inserido em Q e do acesso do extrator a essa forma. Admite-se que o fósforo estimado pelo método compõe a fração lábil.

Os extratores utilizados para predição do fósforo disponível são, normalmente, soluções de reagentes químicos e podem ser classificados em quatro grandes grupos, segundo seus modos de ação. São eles: a) dissolução ácida; b) troca iônica; c) complexação de cátions e d) hidrólise de cátions. Nos extratores do primeiro grupo, que agem por dissolução ácida, são empregados ácidos fortes diluídos ou ácidos fracos, que promovem a dissolução parcial dos colóides inorgânicos, sendo extraídas, em ordem decrescente de efetividade, as formas de fósforo ligadas a cálcio (P$\mathrm{Ca}$ ), a alumínio (P-Al) e a ferro (P-Fe). No segundo grupo de extratores, que agem por troca iônica, estes atuam na substituição do fósforo dos sítios de adsorção dos colóides pelos ânions da solução extratora, sendo normalmente utilizados para isto acetato, bicarbonato, citrato, lactato ou sulfato. Neste grupo de extratores, não há extração preferencial de fósforo de acordo com os tipos de colóides, pois, como é baseado na troca iônica, o princípio mais importante é a energia de ligação com o colóide, e não a capacidade de dissolução do extrator. Já no terceiro grupo de extratores, que agem por complexação de cátions, eles atuam na complexação do metal do grupo funcional dos colóides. Assim, quando a solução extratora contém fluoreto ou alguns ânions orgânicos (citrato e lactato), estes complexam alumínio, sendo extraídas formas de P-Al. Similarmente, o bicarbonato complexa o cálcio (sendo precipitado $\mathrm{CaCO}_{3}$ ), liberando fósforo de compostos P-Ca. No quarto grupo de soluções extratoras que promovem a hidrólise de cátions, a forma de liberação de fósforo dos compostos ocorre em $\mathrm{pH}$ alto devido à adição de ânions hidroxila. Estes ânions dissolvem compostos P-Al e P-Fe pela hidrólise dos cátions ferro e alumínio na superfície dos colóides (SILVA\& RAIJ, 1999).

Dentre os extratores de fósforo existentes, os laboratórios de análise de solo do Brasil utilizam com mais freqüência os de Mehlich 1 e RTA. O primeiro é o método oficial utilizado pela Rede Oficial de Laboratórios de Análise de Solo dos Estados do Rio Grande do Sul e de Santa Catarina. O segundo método é recomendado como uma alternativa para alguns casos especiais nesses dois Estados (CQFS-RS/SC, 2004) e é o método oficial no Estado de São Paulo (RAIJ et al., 2001).

O extrator de Mehlich 1 é composto de uma mistura de ácidos fortes em baixas concentrações $\left(\mathrm{H}_{2} \mathrm{SO}_{4}\right.$ 0,0125 $\mathrm{mol} \mathrm{L}^{-1}$ e $\mathrm{HCl}$ 0,05mol L $\left.{ }^{-1}\right)$, com pH entre 2 e 3. A extração do fósforo ocorre pela dissolução ácida dos compostos fosfatados de fraca energia, sendo maior para fosfatos de cálcio, seguida daqueles ligados ao alumínio e, por último, daqueles ligados ao ferro. $\mathrm{O}$ princípio do método é a dissolução ácida, porém um efeito secundário de troca iônica nos sítios de adsorção também ocorre, no caso, do íon sulfato pelo fosfato. Dentre as principais vantagens da utilização do método Mehlich 1, está sua facilidade de execução e baixo custo de análise. No entanto, deve ser observado que o extrator Mehlich 1 apresenta dois problemas na estimativa dos teores de $\mathrm{P}$ no solo. $\mathrm{O}$ primeiro se refere a uma exaustão da capacidade de extração com o aumento dos teores de argila e do grau de intemperização do solo (NOVAIS \& SMYTH, 1999). Isto foi contornado pela CQFS-RS/SC (2004), que agrupou os solos em quatro classes texturais distintas e criaou uma quinta classe para solos cultivados alagados. Assim, para os mesmos teores de fósforo obtidos em solos argilosos e arenosos, resultam diferentes classes de disponibilidade. O segundo problema é a superestimativa da disponibilidade em solos previamente adubados com fosfatos naturais (GATIBONI et al., 2003). 
No grupo dos agentes de troca iônica, a RTA e o papel impregnado com óxidos de ferro podem ser utilizados para extração do fósforo disponível no solo. No caso do papel impregnado com óxidos de ferro, o fósforo é forçado a sair da fase sólida e ser adsorvido no papel por diferença de concentração. Porém, problemas como a preparação do papel e a baixa quantidade de fósforo extraído são comuns nesta situação (SILVA \& RAIJ, 1999). O método da RTA tem sido utilizado para extração de vários elementos químicos do solo. As resinas são materiais sintéticos de alta massa molecular constituídas de uma matriz polimérica com grupos funcionais responsáveis pela troca de íons. O princípio da extração do fósforo pela RTA é a sua remoção contínua da solução pela troca com o bicarbonato ou cloreto da resina, criando um gradiente de concentração que força a saída da superfície dos colóides, até que seja alcançado um equilíbrio eletroquímico entre o solo e a RTA. SILVA \& RAIJ (1999) consideram que o uso da RTA como extrator de fósforo é adequado para a estimativa do fator quantidade e é melhor que outros extratores porque o processo de extração assemelha-se à ação das raízes das plantas. Além disso, não ocorre perda de força de extração do $\mathrm{P}$ em solos com alto teor de argila, e o uso da RTA não provoca dissolução química de constituintes do solo e evita a superestimação do P disponível em solos que receberam adubação com fosfatos naturais. Porém, RHEINHEIMER et al. (2003b) verificaram que a RTA extraía mais fósforo do que o Mehlich 1 em solos com altos teores de argila e menos naqueles de texturas leves, portanto o método é sensível à textura do solo. Nesse sentido, SCHLINDWEIN (2003) apresentou uma proposta de enquadramento dos teores de fósforo extraído tanto pela RTA como pelo Mehlich 1 em três classes texturais (Figura 1). Em solos com adição de fosfatos naturais, embora a RTA extraia menos fósforo que o Mehlich 1, ela também superestima o fósforo disponível, apresentando baixas correlações com a absorção das plantas (KROTH, 1998). Em virtude do comportamento dos diferentes extratores sobre as formas lábeis de fósforo do solo e da variabilidade de solos que os métodos necessitam atender, a sua eficácia para todas as situações é muito mais dependente dos cuidados na calibração para predição da disponibilidade do que da sua capacidade de extração.

Manejo da adubação fosfatada no sistema plantio direto

A denominação de sistema plantio direto, ou semeadura direta, como preferem alguns, não define, por si só, o manejo adotado no campo. Embora tenha havido avanços significativos no controle da erosão, em muitas áreas ditas de plantio direto, não se adotaram recomendações técnicas na sua implantação, como, por exemplo, a correção da acidez e da deficiência de fósforo da antiga camada arável, o planejamento das estradas e a redefinição dos terraços. A oferta de máquinas e agrotóxicos viabilizou financeiramente a utilização do solo sem revolvimento. Muitos agricultores simplesmente pararam de revolver o solo. Não houve um planejamento adequado da propriedade para a mudança no sistema de cultivo.

Em muitas áreas hoje cultivadas sob sistema plantio direto, os corretivos da acidez do solo e os fertilizantes contendo fósforo são aplicados superficialmente, sem obedecer à predição da análise de solo e/ou às recomendações técnicas. Isso tem se intensificado com a transformação dos campos nativos em áreas de produção de grãos. Quando os teores de fósforo estão acima do teor crítico e, portanto, a probabilidade de resposta das culturas é muito baixa ou ausente, obviamente, não se tem observado perda
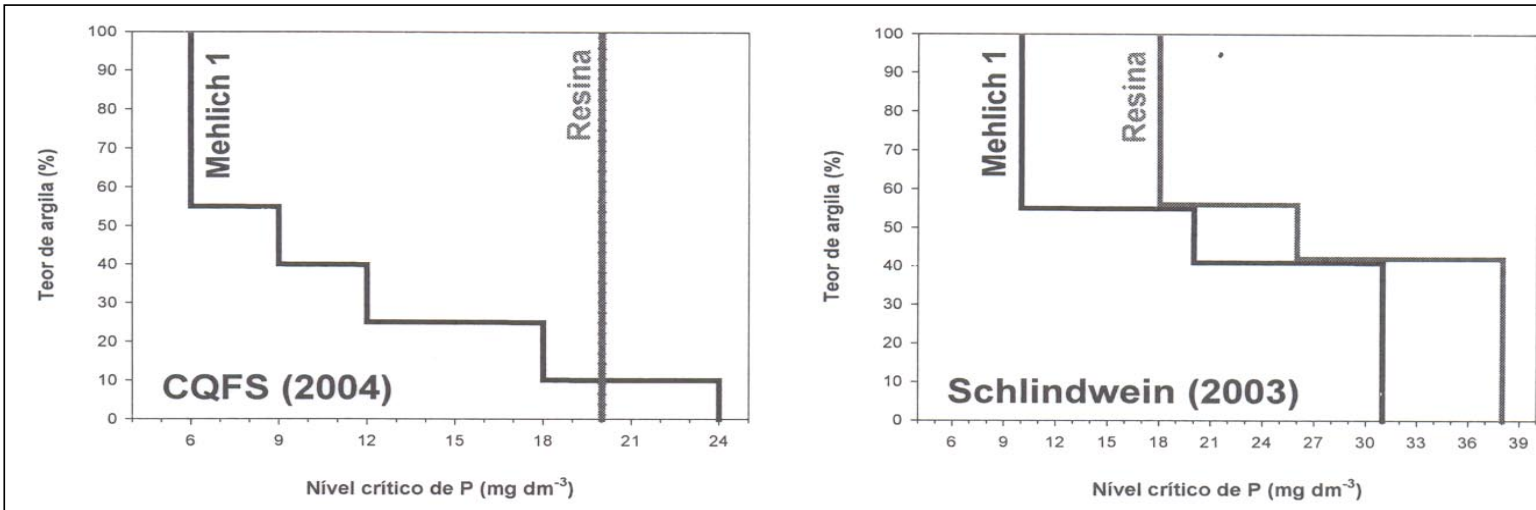

Figura 1 - Níveis críticos de fósforo adotados pela Comissão de Química e Fertilidade do Solo do Núcleo Regional Sul da Sociedade Brasileira de Ciência do Solo para solos sob sistema plantio direto (CQFS-RS/SC, 2004) e níveis críticos propostos por SCHILINDWEIN (2003), baseados no teor de argila do solo. 
de produtividade com a aplicação superficial (ANGHINONI, 1992; PAVINATO \& CERETTA, 2004). No entanto, quando os teores de fósforo estão abaixo do teor crítico, a produtividade tem sido menor que em áreas onde o fosfato foi aplicado na linha de semeadura (POTTKER, 1999). As perdas de produtividade quando da aplicação superficial de fosfato devem ser cada vez maiores à medida que os teores no solo foram menores e em anos com déficit hídrico. Também, tem-se observado o uso de fórmulas de fertilizantes desbalanceadas, aplicadas em quantidades e em épocas inadequadas, que não levam em consideração os resultados das análises de solo, ou por incorreta interpretação dos resultados analíticos, por isso negligenciando as recomendações técnicas.

A tomada de decisão para a aplicação de fertilizantes fosfatados deve ser baseada na análise de solo, a qual pode ser, em alguns casos, auxiliada pela análise de tecido vegetal. O enquadramento de um valor analítico de fósforo numa escala de probabilidade de resposta das culturas à aplicação de fertilizantes fosfatados só será confiável se o procedimento de coleta das amostras de solo for correto. No sistema plantio direto, deve-se considerar que a variabilidade vertical nos atributos químicos e físicos do solo é tanto ou mais importante que a variabilidade espacial horizontal. Assim, a recomendação de que seja coletada amostra do solo da camada $0-10 \mathrm{~cm}$ é única e exclusivamente para se aproveitar os dados de calibração obtidos no cultivo convencional. Assumese que os valores dos atributos de solo da camada 0$10 \mathrm{~cm}$ sob sistema plantio direto sejam equivalentes àqueles da camada $0-20 \mathrm{~cm}$ sob cultivo convencional (CQFS-RS/SC, 2004), considerando-se que o solo das camadas abaixo dos $10 \mathrm{~cm}$ não apresente restrições químicas às plantas.

Para planejar o manejo da adubação fosfatada é indispensável relacionar o resultado da análise do solo com o correto enquadramento na sua classe de disponibilidade. As classes de disponibilidade são obtidas levando em consideração o teor do nutriente no solo e a produtividade das culturas naquelas condições. Por isso, elas são dependentes de um conjunto de experimentos com várias culturas e em diferentes solos, que darão o suporte para a calibração, como mostrado no modelo da figura 2a. Já a dose de fertilizante é estabelecida a partir da quantidade de adubo orgânico ou mineral necessária para que o nível do nutriente alcance valores iguais ao ótimo. As classes de disponibilidade de fósforo adotadas para o sistema plantio direto foram obtidas com informações do cultivo convencional, sem uma calibração própria. Por isso, os valores analíticos podem não ser adequados, já que não se considera no sistema plantio direto a variação dos teores de fósforo e outros atributos químicos ou físicos da camada 10$20 \mathrm{~cm}$ que interferem na produtividade das culturas, especialmente em condições de déficit hídrico. Por outro lado, a maioria dos experimentos de calibração feita no sistema convencional tinha tetos de produtividades hoje considerados médios.

Desse modo, devem-se intensificar as pesquisas enfocando, entre outras: (a) as frações de fósforo no solo e a produtividade das culturas; (b) a melhoria no enquadramento dos valores analíticos nas classes de disponibilidade; (c) as formas de aplicação dos fertilizantes fosfatados no solo sob sistema plantio direto; (d) as relações entre a disponibilidade de fósforo nas camadas subsuperficiais (abaixo de $10 \mathrm{~cm}$ ), a presença de alumínio trocável e de camadas compactadas e (e) o monitoramento constante das transferências de fósforo dos solos aos sistemas aquáticos.

Definição das doses de fertilizantes fosfatados

A definição da dose de fertilizante fosfatado a ser adicionada ao solo depende da filosofia de adubação adotada. Há basicamente duas filosofias de adubação em uso no Brasil: a adubação de correção seguida de manutenção e a construção gradativa da fertilidade do solo. Porém, em qualquer uma delas, visase ao incremento da disponibilidade do fósforo, ou de outro nutriente qualquer, a partir de doses de fertilizantes recomendadas. Por isso, de acordo com o teor no solo, a dose deve ser ajustada para recompor a exportação pela cultura e alcançar ou manter o teor ótimo no solo, como ilustrado na figura $2 \mathrm{~b}$.

A adubação de correção é prática rotineira na implantação do sistema plantio direto no cerrado, mas foi negligenciada na Região Sul. A adubação de correção foi adotada pelo RS e por SC até 1986 e, a partir daí, optou-se pela filosofia da construção gradativa da fertilidade do solo, basicamente, por causa das restrições de crédito para aquisição de fertilizantes. Justamente a partir desse ano é que houve uma grande expansão na área cultivada em sistema plantio direto. Considerando que o sistema plantio direto foi implantado em solos anteriormente manejados sob cultivo convencional ou sob vegetação natural (cerrado ou campo nativo), o solo deveria ter sido preparado para a adoção do sistema, com prévia calagem e adubação de correção. Nesse caso, a dose é definida pela análise do solo. SOUSA et al. (2002) mencionam que, para solos com teor de fósforo na classe muito baixa, deve-se multiplicar o teor de argila por 4 para a 


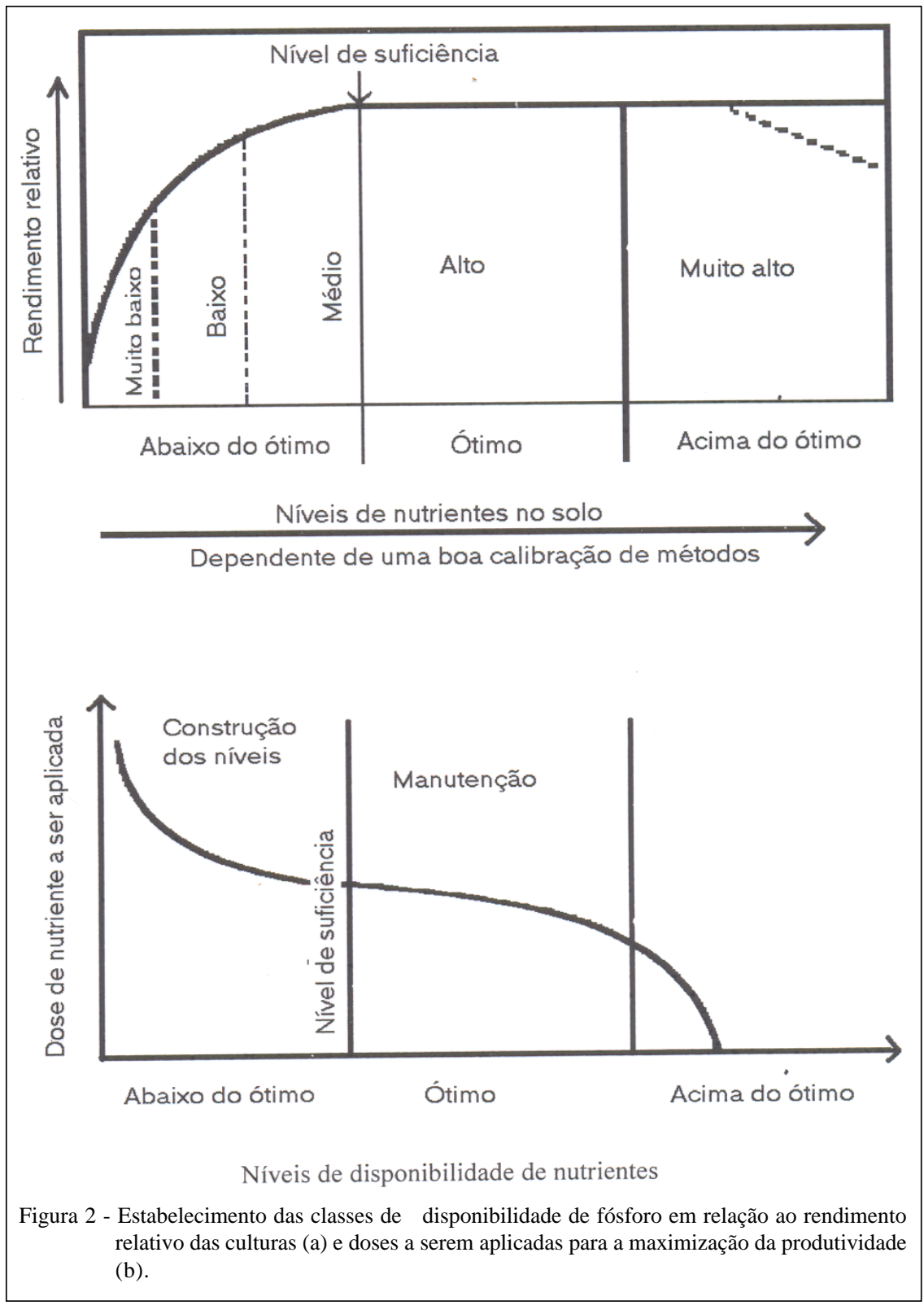

definição da dose de fosfato a ser adicionada para correção total. Para os estados do RS e de SC, quando os teores de fósforo disponíveis forem muito baixos, baixos e médios, a CQFS-RS/SC (2004) também recomenda adubação fosfatada corretiva. As doses são baseadas no poder tampão do solo (120, 60 e $30 \mathrm{~kg}^{\mathrm{P}_{2} \mathrm{O}_{5}}$ $\mathrm{ha}^{-1}$, respectivamente) e representam o somatório das doses de fósforo de dois cultivos sucessivos, descontada a dose de reposição.

Na filosofia de construção da fertilidade, considera-se que a dose de correção deve ser dividida em dois cultivos: 2/3 da dose de correção total no primeiro cultivo e 1/3 no segundo cultivo (CQFS-RS/
SC, 2004). O uso da construção gradativa dos níveis de fósforo disponíveis no sistema plantio direto pode trazer grandes problemas, uma vez que ela foi concebida para o cultivo convencional. Nesse sistema, por ocasião do revolvimento do solo, fazia-se uma homogeneização nos teores de fósforo pelo menos na camada $0-20 \mathrm{~cm}$. No sistema plantio direto, em áreas com classe de disponibilidade abaixo do ótimo, a construção da fertilidade está se dando unicamente na camada superficial, criando um acentuado gradiente de concentração. Conseqüentemente, tem se observado baixo percentual de amostras de solo abaixo de $10 \mathrm{~cm}$ contendo níveis de fósforo disponíveis acima do teor 
crítico (RHEINHEIMER et al., 2003a; MARTINAZZO, 2006).

Os questionamentos que se fazem são: (a) qual a dose a ser aplicada num solo que apresente teor de fósforo na faixa ótima na camada $0-10 \mathrm{~cm}$ e muito abaixo da ótima na camada $10-20 \mathrm{~cm}$ ? e (b) como se espera construir a fertilidade das camadas mais profundas com a aplicação de fosfato a lanço na superfície no sistema plantio direto? Além disso, há trabalhos demonstrando quedas na produtividade de algumas culturas em função de problemas físicos na subsuperfície (SECCO et al., 2004; LIMA et al., 2006; COLLARES et al., 2006), impedindo o acesso ao fósforo, demais nutrientes e água. Nesse sentido, MARTINAZZO (2006) constatou que o solo sob sistema plantio direto apresenta algumas restrições físico-químicas à maximização da produtividade das culturas. Entre elas destacam-se: (a) em torno de um quarto das áreas apresentam problemas de acidez na superfície do solo, porém a metade delas possui alumínio tóxico e baixa saturação por bases nas camadas inferiores, indicando correção efetiva somente na camada superficial; (b) na camada superficial, em torno de dois terços das amostras apresentam teores de fósforo acima do nível de suficiência; (c) nas camadas subsuperficiais aproximadamente três quartos apresentam baixa disponibilidade de fósforo e a metade delas possui saturação por bases inferior a $65 \%$; e (d) todos os locais amostrados apresentam tendência à compactação, em menor ou maior grau, a partir de oito centímetros de profundidade.

A forma de aplicação de fertilizantes fosfatados depende de fatores de solo e de planta. Experimentos desenvolvidos por Barber e seus colaboradores (ANGHINONI \& BARBER, 1980; BORKERT \& BARBER, 1985) demonstram que sempre que as doses de fosfatos forem altas há similaridade de eficiência agronômica com as diferentes formas de aplicação (linha, faixa e lanço). Esses dados foram obtidos com aplicações na linha e a lanço, mas incorporados na camada arável, e não devem ser interpretados como sendo similares aos da aplicação superficial no sistema plantio direto.

No sistema plantio direto tem-se observado que a aplicação de fosfato deve ser feita na linha de semeadura, sempre que houver probabilidade de resposta da cultura à aplicação do fertilizante (disponibilidade de fósforo abaixo do teor crítico) (POTTKER, 1999). Assim, a aplicação superficial fica limitada somente àquelas glebas com teores de fósforo acima do ótimo, pelo menos na camada $0-20 \mathrm{~cm}$; porém, nessa condição, a probabilidade de resposta é muito pequena ou ausente (PAVINATO \& CERETTA, 2004). A época de aplicação dos fertilizantes fosfatados continua sendo no momento da semeadura. Se antecipada, há perda de produtividade (MATINAZZO et al., 2007), pois a energia de ligação do fosfato aos grupos funcionais aumenta com o tempo e, conseqüentemente, diminui a disponibilidade de fósforo às plantas.

\section{CONSIDERAÇÕESFINAIS}

No sistema plantio direto, o diagnóstico da disponibilidade de fósforo às plantas pode ser melhorado considerando-se a distribuição das diferentes formas deste nutriente em todo o volume de solo passível de ser explorado pelo sistema radicular. A adoção do sistema plantio direto a partir do cultivo convencional ou do campo nativo, em muitos casos, não foi adequadamente bem planejada e, conseqüentemente, não se adotaram as recomendações técnicas mínimas sob ponto de vista da Ciência do Solo. Adicionalmente, a forma inadequada de aplicação de fosfatos no solo sob sistema plantio direto vem acarretando aumentos exagerados de fósforo no solo da camada superficial e não tem corrigido a deficiência desse nutriente nas camadas inferiores do solo, onde há predomínio do desenvolvimento radicular. Aliado a isso, as condições químicas do solo (presença de alumínio trocável) e físicas (resistência à penetração, por exemplo) logo abaixo da superfície também não têm sido as mais favoráveis ao crescimento radicular. As pesquisas relacionadas à dinâmica do fósforo devem ampliar o conhecimento científico, especialmente, para melhorar a definição da dose e da forma de aplicação e para o monitoramento das transferências de fósforo aos ambientes aquáticos.

\section{AGRADECIMENTOS}

Ao Conselho Nacional de Desenvolvimento Científico e Tecnológico (CNPQ), pela concessão de bolsa ao pesquisador Danilo Rheinheimer dos Santos.

\section{REFERÊNCIAS}

ANGHINONI, I.; BARBER, S.A. Predicting the most efficient phosphorus placement for corn. Soil Science Society of American Journal, v.44, p.1016-1020, 1980.

ANGHINONI, I. Uso do fósforo pelo milho afetado pela fração de solo fertilizada com fosfato solúvel. Revista Brasileira de Ciência do Solo, v.16, n.2, p.349-353, 1992.

BARROW, N.J. A mechanistic model for describing the sorption and desorption of phosphate by soil. Journal Soil Science, v34, p.733-750, 1983. 
BORKERT, C.M.; BARBER, S.A. Soybean shoot and root growth and phosphorus concentration as affected by phosphorus placement. Soil Science Society of American Journal, v.49, p.152-155, 1985

CHANG, S.C.; JACKSON, M.L. Fractionation of soil phosphorus. Soil Science, v.84, p.133-144, 1957

COLLARES, G.L. et al. Qualidade física do solo na produtividade da cultura do feijoeiro num Argissolo. Pesquisa Agropecuária Brasileira, v.41, p.1663-1674, 2006.

COMISSÃO DE QUÍMICA E FERTILIDADE DO SOLO. Manual de adubação e de calagem para os estados do Rio Grande do Sul e Santa Catarina. SBCS/NRS. Porto Alegre, 2004. 400p.

CONDRON, L.M. et al. Nature and distribution of soi phosphorus as revealed by a sequential extraction method followed by ${ }^{31} \mathrm{P}$ nuclear magnetic resonance analysis. Journal of Soil Science, v.36, p.199-207, 1985.

CONTE, E. et al. Fósforo da biomassa microbiana e atividade de fosfatase ácida pela aplicação de fosfato em solo no sistema plantio direto. Revista Brasileira de Ciência do Solo, v.26, n.4, p.925-930, 2002.

CONTE, E. et al. Frações de fósforo acumulada em latossolo argiloso pela aplicação de fosfato no sistema plantio direto. Revista Brasileira de Ciência do Solo, v.27, n.5, p.893900, 2003.

CROSS, A.F.; SCHLESINGER, W.H. A literature review and evaluation of the Hedley fractionation: Applications to the biogeochemical cycle of soil phosphorus in natural ecosystems. Geoderma, v.64, p.197-214, 1995.

GATIBONI, L.C. et al. Quantificação do fósforo disponível por extrações sucessivas com diferentes extratores em latossolo vermelho distroférrico. Revista Brasileira de Ciência do Solo, v.26, n.4, p.1023-1029, 2002.

GATIBONI, L.C. et al. Superphosphate and rock phosphates as Phosphorus sources for grass-clover pasture on a limed acid soil in Southern Brazil. Communications in Soil Science and Plant Analysis, v.34, n.17/18, p.2503-2514, 2003.

GATIBONI, L.C. et al. Biodisponibilidade de formas de fósforo acumuladas em solo sob sistema plantio direto. Revista Brasileira de Ciência do Solo, v.31, n.4, p.691-699, 2007.

HEDLEY, M.J. et al. Changes in inorganic and organic soil phosphorus fractions induced by cultivation practices and by laboratory incubations. Soil Science Society of American Journal, v 46, p.970-976, 1982.

KROTH, P.L. Disponibilidade de fósforo no solo para plantas e fatores que afetam a extração por resina de troca em membrana. 1998. 168f. Dissertação (Mestrado em Agronomia) - Universidade Federal do Rio Grande do Sul.

LIMA, C.L.R. et al. Qualidade físico-hídrica e rendimento de soja (Glycine max L.) e feijão (Phaseolus vulgaris) de um Argissolo Vermelho distrófico sob diferentes sistemas de manejo. Ciência Rural, v.36, n.4, p.1172-1178, 2006.
MARTINAZZO, R. Diagnóstico da fertilidade de solos em áreas sob plantio direto consolidado. $2006.84 \mathrm{f}$. Dissertação (Mestrado em Ciência do Solo) - Universidade Federal de Santa Maria.

MARTINAZZO, R et al. Fósforo microbiano do solo sob sistema plantio direto afetado pela adição de fosfato solúvel. Revista Brasileira de Ciência do Solo, v.31, n.3, p.563568, 2007

NOVAIS, R.F. et al. Interação entre fósforo pela resina e o fator capacidade deste nutriente no solo. In: REUNIÃO BRASILEIRA DE FERTILIDADE DO SOLO, 18., 1988, Guarapari. Resumos... Campinas: SBCS, 1988. p.109-110.

NOVAIS, R.F.; SMYTH, T.J. Fósforo em solo e planta em condições tropicais. Viçosa: UFV, DPS, 1999. 399p.

PARFITT, R.L. Phosphate reactions with natural allophane, ferrihydrite and goethite. Journal of Soil Science, v.40, p.359-369, 1989.

PAVINATO, P.S.; CERETTA, C.A. Fósforo e potássio na sucessão trigo/milho: épocas e formas de aplicação. Ciência Rural, v34, n.6, p.1779-1784, 2004.

POTTKER, D. Aplicação de fósforo no sistema plantio direto. Passo Fundo: Embrapa, 1999. 32p. (Embrapa Trigo, Boletim de Pesquisa, 2).

RAIJ, B. van. et al. Análise química para avaliação da fertilidade de solos tropicais. Campinas: IAC, 2001. 285p.

RHEINHEIMER, D.S. et al. Fósforo orgânico do solo. In: SANTOS, G.A.; CAMARGO, F.A.O. (Eds). Fundamentos da matéria orgânica do solo: ecossistemas tropicais \& subtropicais. Porto Alegre: Gênesis, 1999. p.139-157.

RHEINHEIMER, D.S. et al. Fósforo da biomassa microbiana em solos sob diferentes sistemas de manejo. Revista Brasileira de Ciência do Solo, v.24, n.3, p.589-597, 2000a.

RHEINHEIMER, D.S. et al. Depleção do fósforo inorgânico de diferentes frações provocada pela extração sucessiva com resina em diferentes solos e manejos. Revista Brasileira de Ciência do Solo, v.24, n.2, p.345-354, 2000 b.

RHEINHEIMER, D.S. et al. Situação da fertilidade dos solos do Rio Grande do Sul. Santa Maria: UFSM, Departamento de Solos, 2001. 41p. (Boletim técnico n 2).

RHEINHEIMER, D.S.; ANGHINONI, I. Distribuição do fósforo inorgânico em sistemas de manejo de solo. Pesquisa Agropecuária Brasileira, v.36, p.151-160, 2001.

RHEINHEIMER, D.S. et al. Organic and inorganic phosphorus as characterized by phosphorus-31 nuclear magnectic resonance in subtropical soils under management systems. Communications in Soil Science and Plant Analysis, v.33, n.13\&14, p.18531871, 2002.

RHEINHEIMER, D.S; ANGHINONI, I. Accumulation of soil organic phosphorus by soil tillage and cropping systems in subtropical soils. Communications in Soil Science and Plant Analysis, v.34, n.15/16, p.2339-2354, 2003. 
RHEINHEIMER, D.S. et al. Sorção de fósforo em função do teor inicial e de sistemas de manejo de solos. Revista Brasileira de Ciência do Solo, v.27, n.1, p.41-49, 2003a.

RHEINHEIMER, D.S. et al. Dessorção de fósforo em sistemas de manejo de solo avaliado por extrações sucessivas com resina trocadora de ânions. Ciência Rural, v.33, n.6, p.1053-1059, 2003b.

SCHLINDWEIN, J.A. Calibração de métodos de determinação e estimativa de doses de fósforo e potássio em solos sob sistema plantio direto. 2003. 169f. Tese (Doutorado em Ciência do Solo) - Universidade Federal do Rio Grande do Sul.
SECCO, D. et al. Produtividade de soja e propriedades físicas de um Latossolo submetido a sistemas de manejo e compactação. Revista Brasileira de Ciência do Solo, v.28, p.797-804, 2004.

SILVA, F.C.; RAIJ, B.V. Disponibilidade de fósforo em solos avaliada por diferentes extratores. Pesquisa Agropecuária Brasileira, Brasília, v.34, p.267-288, 1999.

SOUSA, D.M.G. et al. Adubação com fósforo. In: SOUSA, D.M.G.; LOBATO, E. (Eds). Cerrado: correção do solo e adubação. Planaltina: EMBRAPA, 2002. p147-168.

WALKER, T.W.; SYERS, J.K. The fate of phosphorus during pedogenesis. Geoderma, v.15, p.01-19, 1976. 